\title{
STANDARDISATION OF PIPALIASAVA-A POLYHERBAL FORMULATION
}

\author{
ASHIYANA MANSURI, SONAL DESAI* \\ Department of Quality Assurance, S. S. R. College of Pharmacy, S. S. R. Campus, Sayli Road, Silvassa 396230, India \\ Email: sdesai6381@gmail.com
}

Received: 30 Jul 2016 Revised and Accepted: 07 Dec 2016

\begin{abstract}
Objective: Pipaliasava is a commercially available traditionally fermented biomedicine containing self-generated alcohol. Pipaliasava was standardised for various physicochemical and toxicological parameters using relevant modern techniques.

Methods: Pipaliasava was evaluated for organoleptic and various physicochemical properties. Alcohol content was determined by gas chromatography. The formulation was analysed for the presence of microbial contamination by microbial tests and for heavy metals by atomic emission spectroscopy. HPTLC studies were carried out for quantitative determination of gallic acid in ethyl acetate extract of the formulation.

Results: The formulation was found to be mild acidic. The refractive index was found to be 1.37 . The viscosity was found to be $29.2 \mathrm{cp}$. The solid content was found to be $22.05 \% \mathrm{w} / \mathrm{v}$. Water-soluble extractive value and alcohol-soluble extractive value were evaluated to be $31.664 \% \mathrm{w} / \mathrm{v}$ and $30.424 \% \mathrm{w} / \mathrm{v}$. Reducing and non-reducing sugars were found to be $20.08 \% \mathrm{w} / \mathrm{v}$ and $0.38 \% \mathrm{w} / \mathrm{v}$. The content of ethanol was found to be $8.29 \%$ using GC technique. Different extracts of pipaliasava were evaluated for the presence of various phytoconstituents using respective chemical tests. The formulation showed the absence of lead and mercury and permissible levels of arsenic and cadmium. The formulation showed no presence of $E$. coli, P. aerugenosa and S. aureus in the microbiological examination. Gallic acid content in the ethyl acetate extract of pipaliasava was found to be $0.0061 \%$ by HPTLC.
\end{abstract}

Conclusion: Marketed pipaliasava formulation was successfully standardized as per Ayurvedic Pharmacopoeia of India and WHO guidelines.

Keywords: Gallic acid, Pipaliasava, Marker compound, Standardisation

(C) 2016 The Authors. Published by Innovare Academic Sciences Pvt Ltd. This is an open access article under the CC BY license (http://creativecommons.org/licenses/by/4. 0/) DOI: http://dx.doi.org/10.22159/ijpps.2017v9i2.14416

\section{INTRODUCTION}

Ayurveda, the oldest and richest system of medicine practiced worldwide, uses medicinal plants in different forms for prevention and treatment of many diseases. Unlike allopathic drugs, herbal drugs are available at a fair price and possess nominal side-effects. According to a survey made by WHO, herbal medicines are used by $80 \%$ of world population for primary health care [1]. Lack of rigid quality control procedures for herbal drugs and formulations is one of the major problems faced by the herbal industry [2-3]. WHO has also laid down a number of resolutions to highlight the need to ensure quality control of medicinal plant products using advanced analytical techniques and applying suitable standards. Standardisation involves the development of set of standards for various parameters to ensure quality, safety and efficacy of the drugs [4-6].

Asavas are fermented liquid preparations containing medicinal plants. During preparation of asava, alcohol is generated. The self-generated alcohol ensures effective extraction of active principles from crude medicinal plants and also prevents the growth of microorganism [7-8]. Pipaliasava is over the counter product widely used as a carminative, stomachic and for the treatment of a cough and dysentery.

This paper discusses systematic standardisation procedure for pipaliasava using modern analytical techniques.

All the solvents were of AR grade and were purchased from Thermo Fischer Scientific, Mumbai. Marketed preparation of pipaliasava (Baithyanath) was procured from a local pharmacy of Silvassa. Standard of gallic acid (Purity $98 \% \mathrm{w} / \mathrm{w}$ ) was procured from Sigma Aldrich. Precoated silica plates GF254 were purchased from E. Merck.

Pipaliasava was initially evaluated for organoleptic characteristics like appearance, colour, odour and taste. The formulation was palatable with agreeable odour and taste. The formulation was weakly acidic. $\mathrm{pH}$, viscosity and the refractive index of pipaliasava were determined using calibrated digital $\mathrm{pH}$ metre (Equiptronics EQ-610), calibrated viscometer (Fungilab Expert L-series) and
Abbe's refractometer (Rajdhani RSR-1), respectively. Specific gravity of pipaliasava was determined using a calibrated pycnometer of 10 ml capacity [9]. Each measurement was carried out in triplicate.

For determination of solid content, pipaliasava $(50 \mathrm{ml})$ was evaporated to a thick extract on a water bath. The residue was further extracted with alcohol (4 X $10 \mathrm{ml})$. The alcohol extracts were pooled together, evaporated to dryness and weight was determined. For alcohol-soluble extractive value, Pipaliasava (5 ml) was macerated with $100 \mathrm{ml}$ of alcohol, filtered and $25 \mathrm{ml}$ of the filtrate was evaporated to dryness and weight was determined. The percentage of alcohol-soluble extractive with reference to pipaliasava was calculated. For water soluble extractive value, water containing $2.4 \%$ of chloroform was used instead of alcohol and procedure were repeated. The experiment was repeated thrice.

For determination of reducing sugars, pipaliasava $(20 \mathrm{ml})$ was transferred into a $250 \mathrm{ml}$ conical flask and $\mathrm{pH}$ was adjusted using $10 \%$ $\mathrm{NaOH}$. The solution was evaporated to half the volume to eliminate the alcohol and again the volume was made up to $100 \mathrm{ml}$ with distilled water. This solution was used as titrant for $10 \mathrm{ml}$ of the Fehling's solution boiling over a hot plate until the mixture turned blue. Then few drops of $1 \%$ methylene blue were added and titration was continued till the blue colour changed to brick red colour. Titration was carried out thrice and the amount of reducing sugars was determined.

For determination of non-reducing sugars, pipaliasava $(20 \mathrm{ml})$ was transferred into a $250 \mathrm{ml}$ conical flask and $\mathrm{pH}$ was adjusted using 10 $\% \mathrm{NaOH}$. The solution was evaporated to half the volume and $15 \mathrm{ml}$ of $0.1 \mathrm{~N} \mathrm{HCl}$ was added. The resulting solution was boiled for two minutes. The solution was neutralised with $10 \% \mathrm{NaOH}$ and volume were made up to $100 \mathrm{ml}$ with distilled water. This solution was used as titrant for reduction of Fehling's solution and the procedure was repeated as performed for reducing sugars. The amount of total sugars was calculated. The amount of non-reducing sugars was obtained by deducting the amount of the reducing sugars from total sugars [10]. Table 1 represents results of evaluation of various physicochemical properties of the formulation. 
Headspace gas chromatography technique was used for determination of alcohol using Perkin Elmer Clarus 500 gas chromatograph. The analysis was carried out using column DB$624(30 \mathrm{~m}$ X $0.25 \mathrm{~mm}, 1.40 \mu \mathrm{m})$. Nitrogen was used as carrier gas at a flow rate of $2 \mathrm{ml} / \mathrm{min}$. Injector port and detector were equilibrated at $140{ }^{\circ} \mathrm{C}$ and $220^{\circ} \mathrm{C}$, respectively. For headspace, the oven temperature was kept at $95^{\circ} \mathrm{C}$; needle temperature was kept at $100{ }^{\circ} \mathrm{C}$ and pressure of carrier gas was kept at 15.4 psi.
Ethanol solutions were prepared in the range of 1000-3000 $\mu \mathrm{g} / \mathrm{ml}$ in dimethylformamide (DMF). For sample preparation, pipaliasava $(1 \mathrm{ml})$ was taken in $50 \mathrm{ml}$ volumetric flask and volume was made up to the mark with DMF and injected in triplicate. The concentration of alcohol in pipaliasava was calculated using regression analysis. In GC analysis, alcohol eluted with a mean retention time of $7.94 \mathrm{~min}$ (fig. 1). Ethanol content in the given formulation of pipaliasava was found to be $8.29 \%$.

Table 1: Evaluation of physicochemical parameters

\begin{tabular}{lll}
\hline S. No. & Physicochemical parameter & Observations $^{\mathbf{a}}$ \\
\hline 1 & Description & Dark brown coloured liquid with an aromatic odour, acrid taste and with some sediments. \\
2 & pH & 4.4 \\
3 & Viscosity & $29.2 \mathrm{cps}$ \\
4 & Refractive index & 1.37 \\
5 & Specific gravity & 1.06 \\
6 & Solid content & $22.05 \% \mathrm{w} / \mathrm{v}$ \\
7 & Alcohol-soluble extractive value & $30.424 \% \mathrm{w} / \mathrm{v}$ \\
8 & Water-soluble extractive value & $31.664 \% \mathrm{w} / \mathrm{v}$ \\
9 & Reducing sugars & $20.08 \% \mathrm{w} / \mathrm{v}$ \\
10 & Non-reducing sugars & $0.38 \% \mathrm{w} / \mathrm{v}$ \\
11 & Ethanol content by GC & $8.29 \%$ \\
\hline
\end{tabular}

$\mathrm{a}=$ mean of 3 measurements

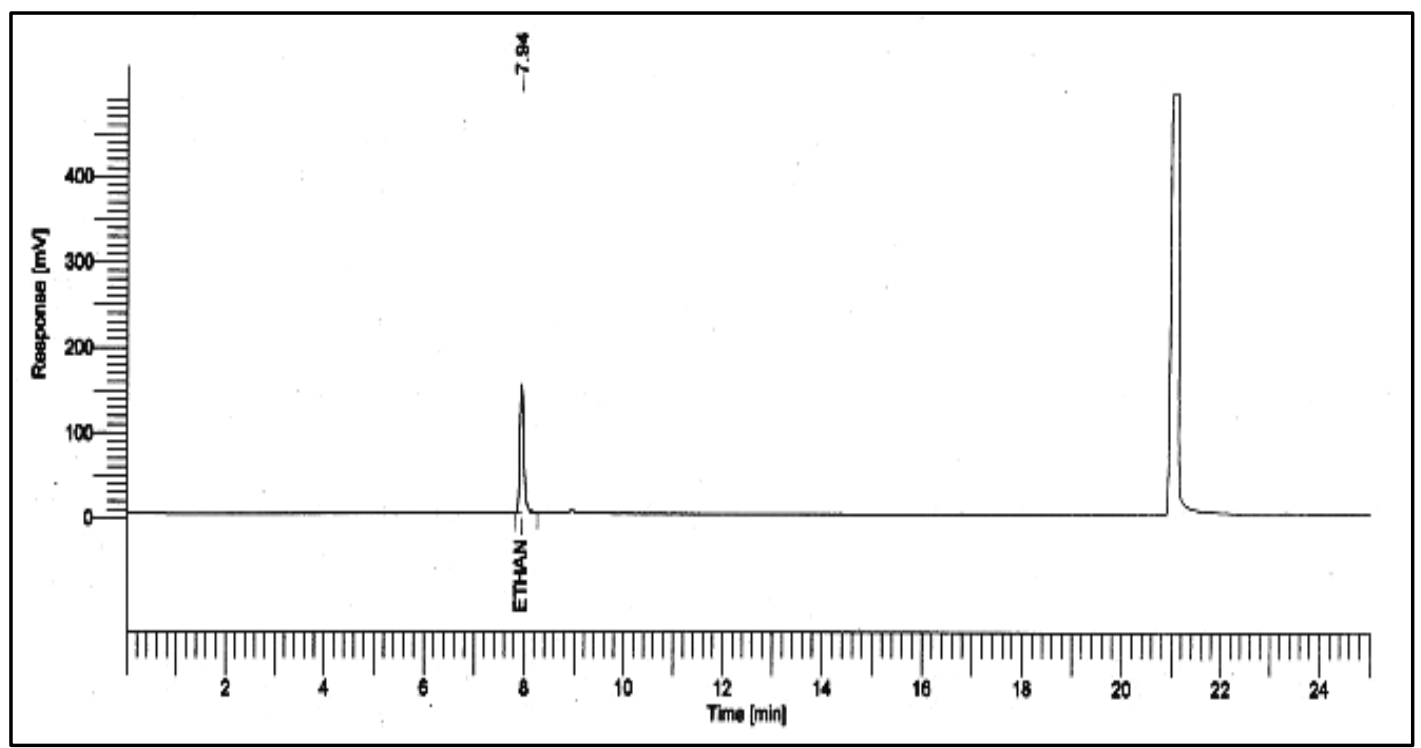

Fig. 1: Gas chromatogram of pipaliasava

The formulation was also evaluated for phytochemical screening. Pipaliasava (100 ml) was evaporated to half of its volume, cooled and was diluted to $100 \mathrm{ml}$ with distilled water. This aqueous solution was successively extracted with various solvents in increasing polarity such as petroleum ether $\left(60-80^{\circ} \mathrm{C}\right)$, chloroform, ethyl acetate and methanol. Each extract was evaluated for the presence of various phytoconstituents [11]. Successive extracts were prepared using organic solvents and were screened for the presence of phytoconstituents (table 2).

Table 2: Phytochemical screening of successive extracts of pipaliasava

\begin{tabular}{|c|c|c|c|c|c|}
\hline S. No. & Phytoconstituent & Petroleum ether extract & Chloroform extract & Ethyl acetate extract & Methanol extract \\
\hline 1 & Alkaloids & - & + & + & + \\
\hline 2 & Carbohydrates & - & + & + & - \\
\hline 3 & Glycosides & - & - & + & - \\
\hline 4 & Flavonoids & - & - & + & + \\
\hline 5 & Phenols & + & - & + & + \\
\hline 6 & Tannins & - & - & + & - \\
\hline 7 & Steroids & - & - & - & - \\
\hline 8 & Amino acids & - & + & - & - \\
\hline
\end{tabular}

(+indicates positive test,-indicates negative test). 
Atomic emission spectroscopy (PerkinElmer Optima 2100 DV) was used for determination of heavy metals such as arsenic, cadmium, mercury and lead. Radio Frequency power supply was kept at 1300 watts. The nebuliser was kept at $0.8 \mathrm{l} / \mathrm{min}$. Argon at the flow rate of 15 $1 /$ min was utilised as plasma. Auxiliary gas $\left(\mathrm{N}_{2}\right)$ flow rate was maintained at $0.2 \mathrm{l} / \mathrm{min}$. Standard solutions of all heavy metals were prepared in the range of $0.05-2.0 \mu \mathrm{g} / \mathrm{ml}$ by diluting with an acid blank solution of conc. $\mathrm{HCl}$ and conc. $\mathrm{HNO}_{3}$ (3:1). For sample solution, $5 \mathrm{ml}$ of pipaliasava was mixed with the acid blank solution and digested at 80 ${ }^{\circ} \mathrm{C}$ for $30 \mathrm{~min}$. The resulting solution was allowed to cool at room temperature and volume was made up to $50 \mathrm{ml}$ with deionised water. The resulting solutions were subject to heavy metal analysis. Heavy metal analysis showed the absence of lead and mercury, arsenic and cadmium were present within standard limits (table 3).

Table 3: Evaluation of heavy metals as per WHO guidelines

\begin{tabular}{llll}
\hline S. No. & Heavy metal & Standard value & Observed value $^{\mathbf{b}}$ \\
\hline 1 & Lead (Pb) & $10 \mu \mathrm{g} / \mathrm{ml}$ & Not detected \\
2 & Arsenic (As) & $10 \mu \mathrm{g} / \mathrm{ml}$ & $0.0247 \mu \mathrm{g} / \mathrm{ml}$ \\
3 & Mercury (Hg) & $1 \mu \mathrm{g} / \mathrm{ml}$ & Not detected \\
4 & Cadmium (Cd) & $0.20 \mu \mathrm{g} / \mathrm{ml}$ & $0.0186 \mu \mathrm{g} / \mathrm{ml}$ \\
\hline
\end{tabular}

$\mathrm{b}=$ mean of 3 measurements

The sample of pipaliasava was evaluated for microbial contamination as per WHO guidelines. Total aerobic microbial count, E. coli, P. aerugenosa and $S$. aureus were evaluated by pour plate technique [12-
13]. In the microbial examination, P. aerugenosa, E. Coli and S. aureus were found to be absent while total aerobic count and total yeast and mould count were within limits specified by WHO (table 4).

Table 4: Evaluation of microbial load as per WHO guidelines

\begin{tabular}{llll}
\hline S. No. & Micro-organism & Permissible limit & Observed value $^{\mathbf{c}}$ \\
\hline 1 & Aerobic viable aerobic count & $10^{5} \mathrm{cfug}^{-1}$ & $192 \mathrm{cfug}^{-1}$ \\
2 & Total yeast and mould count & $10^{3} \mathrm{cfug}^{-1}$ & $86 \mathrm{cfug}^{-1}$ \\
3 & E. coli & $10^{1} \mathrm{~g}^{-1}$ & $\mathrm{Absent}$ \\
4 & P. aerugenosa & $\mathrm{Absent}$ & $\mathrm{Absent}$ \\
5 & S. aureus & Absent & Absent \\
\hline
\end{tabular}

$\mathrm{c}=$ mean of 3 measurements

In preliminary TLC studies, ethyl acetate extract revealed the presence of gallic acid (fig. 2). Hence the ethyl acetate extract was quantified for gallic acid content by HPTLC.

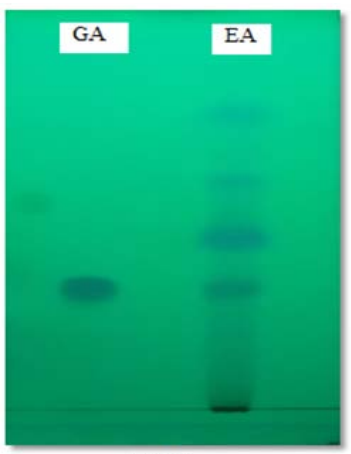

(a) $254 \mathrm{~nm}$

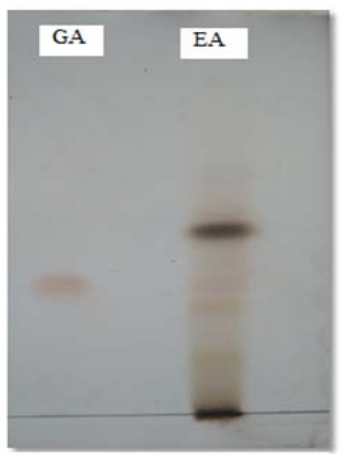

(b) after spraying with $5 \% \mathrm{FeCl}_{3}$ solution
$\mathrm{GA}=$ Standard Gallic acid $\mathrm{EA}=$ Ethyl acetate extract

Fig. 2: TLC images of standard gallic acid and ethyl acetate extract of pipaliasava

HPTLC studies were carried out by CAMAG III HPTLC system. In HPTLC studies, precoated Silica Gel GF245 plates (E. Merck)) $(20 \mathrm{~cm}$ $\mathrm{X} 10 \mathrm{~cm}$ ) were utilised as the stationary phase. Toluene: ethyl acetate: formic acid (10:7:1, v/v/v) was used as mobile phase. Gallic acid solutions were prepared in the range of $20-60 \mu \mathrm{g} / \mathrm{ml}$ using methanol as solvent. Ethyl acetate extract was dissolved in $20 \mathrm{ml}$ ethyl acetate, sonicated for $5 \mathrm{~min}$ and filtered. All the solutions were applied as $5 \mathrm{~mm}$ bands with band distance of $10 \mathrm{~mm}$ with the help of LINOMAT V applicator. Injection volume for each band was $20 \mu \mathrm{l}$. Chamber was saturated with mobile phase for $15 \mathrm{~min}$. Plates were developed in ascending mode and detection was carried out at 271 nm using CAMAG Scanner 3. HPTLC dendrograms of standard gallic acid and ethyl acetate fraction of pipaliasava are shown in fig. 3 and fig. 4, respectively.

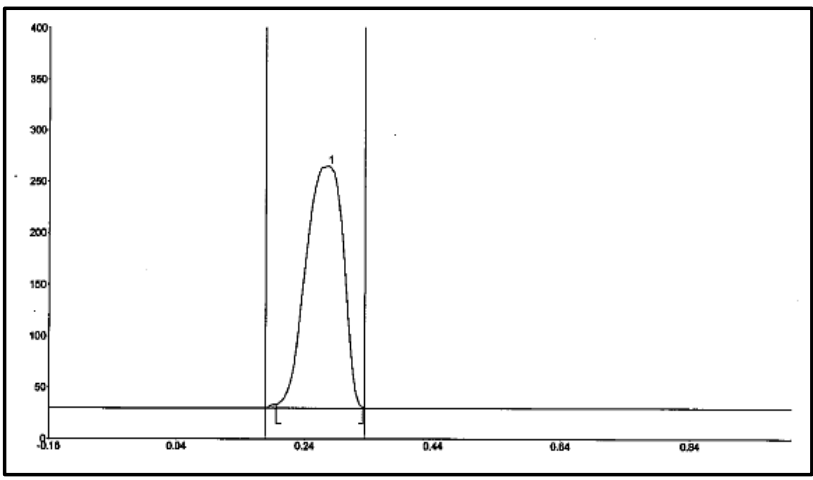

Fig. 3: HPTLC densitogram of gallic acid

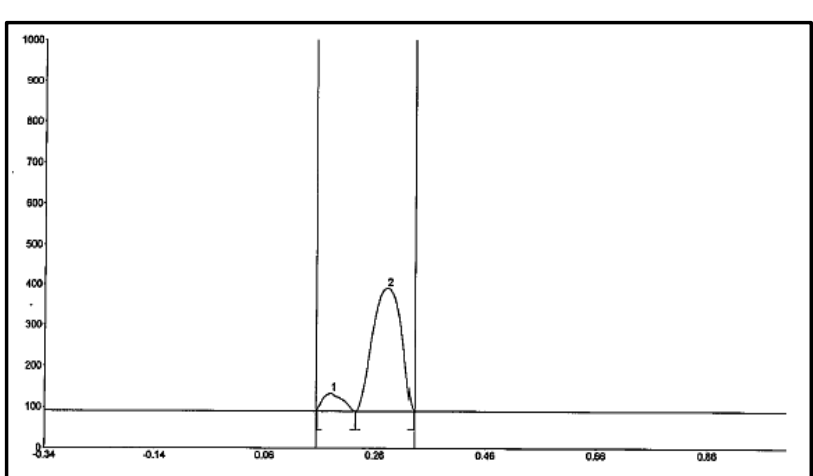

Fig. 4: HPTLC densitogram of ethyl acetate fraction of pipaliasava 
A calibration curve was prepared for area Vs concentration and quantity of gallic acid in ethyl acetate extract was calculated. Gallic acid content in pipaliasava was found to be $0.0061 \%$ by HPTLC.

Thus, the marketed pipaliasava was standardised as per Ayurvedic Pharmacopoeia of India and WHO guidelines. The formulation passes all the physicochemical tests and is also within the permissible limits of heavy metals and microbial contamination.

\section{CONFLICT OF INTERESTS}

Declared none

\section{REFERENCES}

1. Subhose V, Srinivas P, Narayana A. Basic principles of pharmaceutical science in Ayurveda. Bull Indian Inst Hist Med 2005;35:83-2.

2. Kunle OF, Egharevba HO, Ahmadu PO. Standardization of herbal medicines a review. Int J Biodivers Conserv 2012;4:101-12.

3. Rasheed A, Reddy SB, Roja C. A Review on standardisation of herbal formulation. Int J Phytother 2012;2:74-8.

4. Neeraj C, Bhupinder S. An overview of advances in the standardisation of herbal drugs. J Pharm Educ Res 2011;2:55-72.

5. Satheesh NV, Upadhyaya K, Bisht A. Phytochemical screening and standardisation of polyherbal formulation for dyslipidemia. Int J Pharm Pharm Sci 2011;3:235-8.
6. Sharma AK, Gaurav SS, Balkrishna A. A rapid and simple scheme for the standardization of polyherbal drugs. Int J Green Pharm 2009;3:134-40.

7. Nandre BN, Bakliwal SR, Rane BR, Pawar SP. Traditionally fermented medicines-Asava and Arishta. Int J Pharm Biol Sci Arch 2012;3:1313-9.

8. Sekar S, Mariappan S. Traditionally fermented biomedicinesarishtas and asavas from ayurveda. Indian J Tradit Know 2008;7:548-56.

9. More HN, Hajare AA. Practical physical pharmacy. $1^{\text {st }}$ ed. Nashik: career Publications; 2007.

10. Anonymous. The ayurvedic pharmacopoeia of India. Part II. Vol II. New Delhi: Controller of publication; 1978.

11. Khandelwal KR. Practical pharmacognosy techniques and experiments, Pune: Nirali Prakashan; 2006.

12. Masand S, Madan S, Balian SK. Modern concepts of storage and packaging of raw herbs used in Ayurveda. Int J Res Ayurveda Pharm 2014;5:242-5.

13. WHO guidelines for assessing the quality of herbal medicines with reference to contaminants and residues. Geneva: WHO Press; 2007.

\section{How to cite this article}

- $\quad$ Ashiyana Mansuri, Sonal Desai. Standardisation of pipaliasavaa polyherbal formulation. Int J Pharm Pharm Sci 2017; $9(2): 308-311$ 